\title{
A Case Study of Problem-Based Learning for University Physics
}

\author{
Xue-mei Cui \\ Normal College, Yanbian University \\ Yanji, China \\ xmcui@ybu.edu.cn
}

\author{
Seung Kee Han \\ Department of Physics, Chungbuk National University \\ Cheongju, Korea \\ skhan@chungbuk.ac.kr
}

\begin{abstract}
This article is a report on the results of applying problem-based learning (PBL) strategy to students who study the course computational physics at a four-year college in Korea. As a result of applying PBL to the class of Computational Physics, students have a good effect on the way of (1)understanding of the content; (2)self-learning ability and cooperative learning ability; (3)interest in science; (4)methods and ability to solve scientific problems in daily life. However, it suggested that a successful PBL process should be based on proper interpretation, guidance, and programming fundamentals.
\end{abstract}

Keywords-PBL; university physics courses; self-learning ability; computational physics

\section{INTRODUCTION}

Problem-based learning (PBL) was developed in medical education area in 1950s and has been developed for using in various disciplines and educational settings [1-7].PBL is a learner-centered teaching-learning combining strategy in which solving the unstructured problems through cooperation among students in a practical context [3].In the course of learning, students are challenged to unstructured problems based on their own experiences and knowledge, self-directed learning is performed, and teachers serve as assistant in learning [2].

The PBL has the following elements. (1)The beginning of learning is 'problem', and the essence of learning is based on problem solving. (2)The 'problem' should be the unstructured problem in the real world and there should be no settled solution and process. (3)Developing cooperative and intercultural competence through mainly self-directed learning and team learning. (4)Focusing on the learners in whole process and the student should be able to take responsibility for learning. (5)The role of the teacher is a guide for teaching cognitive learning skill. (6)Self-evaluation and team evaluation should be done, after each problem is solved.

\section{THE CLASS DESIGN}

"Computational Physics" is a major course in the Department of Physics at a Korean University. Students learn the functions of scientific computation and simulation based on MATLAB. Students learn fundamental problems and nonlinear problems learned in physics. The goal is to develop the ability to solve physical problems through numerical analysis by developing modeling, programming, and summing abilities.
In order to achieve the goal above, we learned how to solve differential equations by MATLAB and numerical methods for two weeks, after it the courses were conducted around the PBL.As mentioned earlier, the PBL is a learner-centered learning method in which students solve problems with self directed learning and collaborative learning. We expect PBL show diversity in information retrieval, data collection and processing, problem solution and so on. The most important factor of PBL, the 'problem', teachers is to start from a relatively simple non-structural problems in accordance with the actual level of the students, choose the three problems following.

\section{A. The Coffee Cooling Problem}

How much time does the coffee in the cup cool down? What kind of material would slow down the speed of the coffee cooling down?

\section{B. Motion of Falling Objects}

The ideal motion of falling objects can be described by an equation. Let's study whether the parabolic motion follows the theory when we see in daily life, that is, when there is air resistance.

\section{The Kepler Problem}

Try verifying the Kepler's Law of Physics about planetary motion released by the German astronomer Johannes Kepler, and get the Earth's orbit.

With solving the above three problems, the problem solving methods, abilities and functions are improved, and the students select the problems according to their interests. Conducting self evaluation and mutual evaluation after each problem is solved.

PBL classes were divided into teams of 2 3 students and conducted in the computer room. Data collection for problem solving was conducted mainly in private tutoring, and data processing, analysis and presentation were conducted during the class.

\section{Classes WITH PBL}

We introduce the process of applying PBL among classes as the second example above.

First of all, it is important to teach the characteristics and installation of MATLAB which is the main tool, matrix creation and mathematical operation, use of if statement, for 
statement, while statement, use of graphic function, use of $\mathrm{M}$ file, Euler Method and Runge-Kutta method to solve differential equations and dynamic mapping methods. MATLAB is high-performance numerical calculations and able to visualize the results, making it a very useful for problem solving.

\section{A. The problem}

The parabolic movement has taught since middle school. The parabolic movement that students have learned is an ideal parabolic movement that ignores air resistance and is different from the parabolic movement in real life. We need to know the actual parabolic motion as living in the real world. It is suitable for a problem in PBL.

\section{B. Solutions and processes}

\section{1) Actual parabolic trajectory photographing}

The first data should be collected to solve the problem is actually a parabolic trajectory. The first mission of every team is to photograph the real parabolic trajectories. For collecting data after photographing, discussing with teammates and communicate with other teams about what to take care of at the time of photographing, the teacher submitted the following request.

- The contrast of the color of the moving object and the background color should be high.

- Note that the resolution of the imaging device also affects obtaining the correct trajectory.

- The actual length of the specific object (for example, the height of the basketball hoop or the height of the person throwing the basketball) should be measured during photographing for conversion between pixel unit and actual distance.

Even though we submitted these requests, some of the teams need photograph the images again because of lack of resolution or low contrast between object and background. After two or three more attempts, each team got a parabolic trajectory of objects such as basketball, soccer, baseball, vinyl ball, and water rocket.

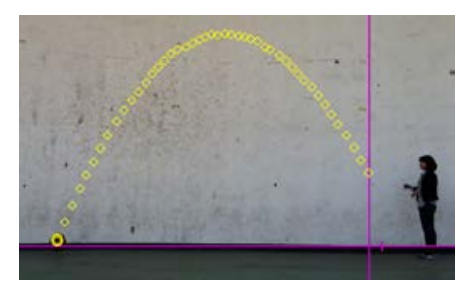

(a)

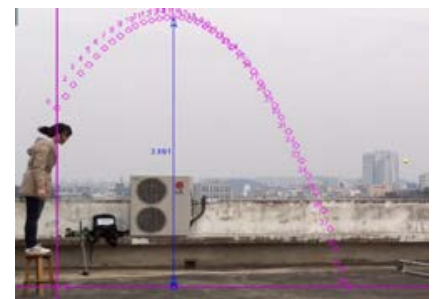

(b)
Fig. 1. Parabolic motion video taken by students

\section{2) Obtaining actual parabolic trajectory data}

How can we get the trajectory data from a captured parabolic video? As a result of searching the trajectory recording program for each team and processing the data, a program called Tracker which is easy to install and use was used for several teams. Position the target in the captured video and input pixel-per-pixel value to get the actual coordinate value over time.

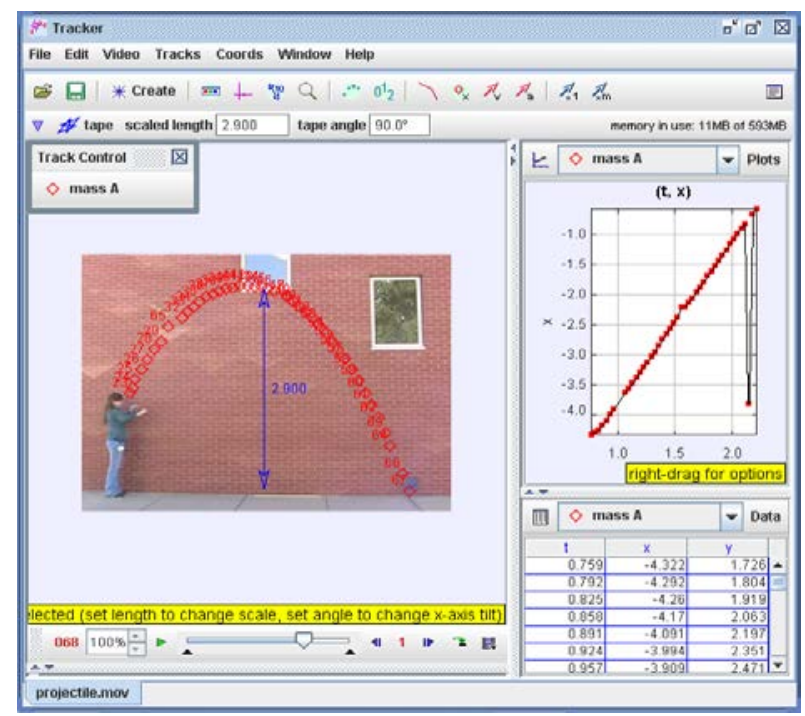

Fig. 2. The user interface of trajectory recording program 'Tracker'

\section{3) Modeling the actual parabolic motion}

In this section, students should model the actual parabolic motion considering the element of air resistance with the preliminary knowledge of the ideal parabolic motion. It is the process of dealing with important theoretical knowledge that necessary to solve this problem. Need some teacher's guide. For teams and students may have different learning difficulties, so the teacher must ensure that all students understand the theoretical knowledge through the appropriate guide.

The parabolic motion is a two-dimensional motion. When the air resistance is neglected, the equation can be written on the $\mathrm{x}$ and $\mathrm{y}$ axes by the second law of Newton as follow.

$$
\left\{\begin{array}{l}
m \frac{d^{2} x}{d t^{2}}=F_{x}=0 \\
m \frac{d^{2} y}{d t^{2}}=F_{y}=-m g
\end{array}\right.
$$

To solve equation (1) by numerical method, write it as first order differential equation as follows.

$$
\begin{cases}\frac{d x}{d t}=v_{x}, & \frac{d v_{x}}{d t}=a_{x}=0 \\ \frac{d y}{d t}=v_{y}, & \frac{d v_{y}}{d t}=a_{y}=-g\end{cases}
$$

Knowing the initial conditions $x(0), y(0), v_{x}(0), v_{y}(0), t_{\text {start }}$, $\mathrm{t}_{\text {end }}$, the acceleration $a_{x}, a_{y}$ can be calculated, so the speed and location of the next time can be known. 


$$
\left\{\begin{array}{l}
x(t+d t)=x(t)+d t \times \frac{d x}{d t}=x(t)+d t \times v_{x}(t) \\
y(t+d t)=y(t)+d t \times \frac{d y}{d t}=y(t)+d t \times v_{y}(t) \\
v_{x}(t+d t)=v_{x}(t)+d t \times \frac{d v_{x}}{d t}=v_{x}(t)+d t \times a_{x}(t) \\
v_{y}(t+d t)=v_{y}(t)+d t \times \frac{d v_{y}}{d t}=v_{y}(t)+d t \times a_{y}(t)
\end{array}\right.
$$

In actual parabolic motion, the air resistance can be expressed as $b \boldsymbol{v}$ (b is the coefficient of resistance), which is directly proportional to the velocity.

$$
\boldsymbol{F}=m \boldsymbol{a}-b \boldsymbol{v}=m\left(\boldsymbol{a}-\frac{b}{m} \boldsymbol{v}\right)
$$

At this time, the acceleration in the $x$ and $y$ axes is as follows.

$$
\left\{\begin{array}{l}
a_{x}=-\frac{b}{m} v_{x} \\
a_{y}=-g-\frac{b}{m} v_{y}
\end{array}\right.
$$

Changing ax, ay from equation (2) to equation (5) can get an actual parabolic model considering air resistance. Initial condition can estimated by the following equation as the first data and second data.

$$
\left\{\begin{array}{l}
v_{x}(1)=\frac{x(2)-x(1)}{t(2)-t(1)} \\
v_{y}(1)=\frac{y(2)-y(1)}{t(2)-t(1)}
\end{array}\right.
$$

After analyzing and processing the data above, the actual parabolic trajectory and the modeled parabolic trajectory are shown as Fig. 3. As can be seen in the figure, the actual parabolic trajectory is shifted downwards from the ideal parabolic trajectory, and the resistance coefficient is about 0.163.To obtain the exact resistance factor corresponding to the actual trajectory, a least squares regression analysis can be used.

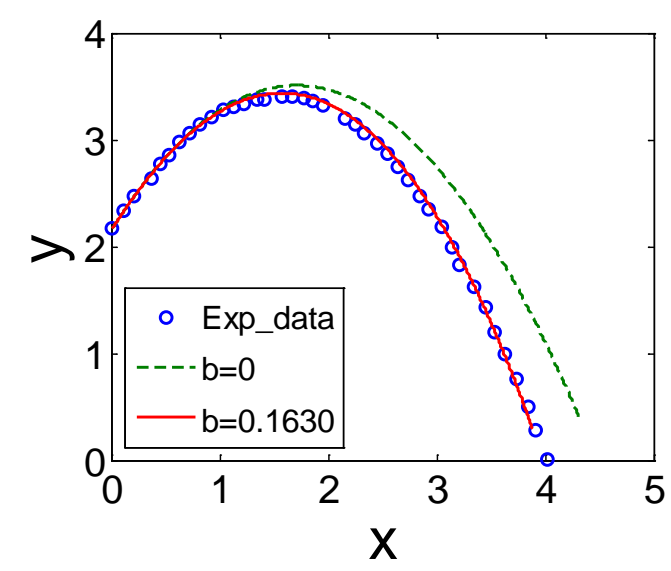

Fig. 3. Actual parabolic trajectory and modeled parabolic trajectory(The actual parabolic trajectory data is displayed the blue circle,The data indicated by the green dotted line indicate the locus when the air resistance is ignored, The data indicated by the red solid line indicate the trajectory)

\section{Self-directed, Team communication and Cooperative learning situation}

After accepting the problem for each team, first thought about a plan for solving the problem, information to collect and difficulties encountered. Then, the members of the team discussed and cooperated with each other to submit a solution plan for each team. There may be some problems that can't be solved by the students. First, Solving the problems through team communication, and problems that can't be solved finally, solve them through proper presentation and guidance of teachers.

In the case of students' self-directed learning ability being expressed well in problem solving process, students of one team explored the correlation factor of resistance coefficient using different volume and material balls to compare resistance coefficients of different balls. In order to measure the length of a specific object, the right team of Fig.1 used the method of throwing on the top of the chair. These measures help students to solve problems that they have always wondered in daily life, it also demonstrate their wisdom to solve more scientific problems.

In the process of problem solving, inner-team communication and inter-team communication have a very large effect. Many problems encountered during the problemsolving process were solved through the communication in inner-team and inter-team. Students became able to interact and collaborate with each other through the process.

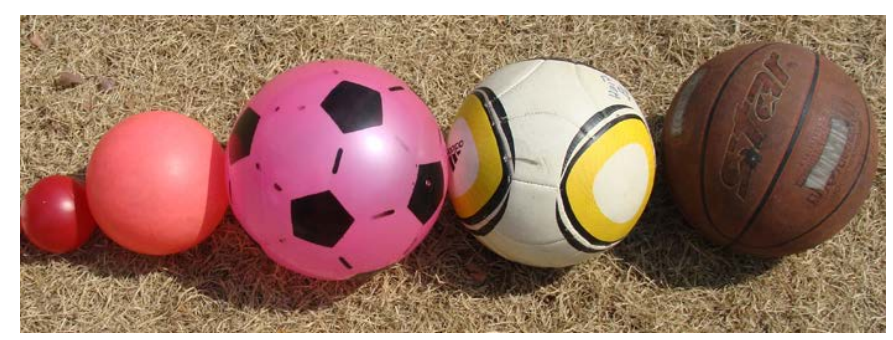

Fig. 4. Different balls used for resistance coefficient comparison

\section{Teacher's Role}

In PBL, the teacher is a guide to guide students' cognitive learning skills. First, it is most important to choose a "problem" that match with the interests and abilities of the students. In order to do this, teachers need to know students' cognitive level and enjoyment well.

To teach students cognitive learning skills, teacher should research how to direct such knowledge and skills on the basis of what knowledge and skills are needed in the PBL problemsolving process. As different levels of students are needed for different levels of instruction, the teacher must prepare a lot for level instruction in advance.

\section{E. Evaluation}

During the course of one semester, one assistant identified the learning difficulties of the students on time by observing and interviewing, and the students were able to adapt smoothly to the PBL-applied lessons, and the learning effects could reach our expectations. 
At the beginning of the semester, the main difficulty for students was the use of MATLAB and programming. The students who participated in the class did not learn MATLAB before the class, and some students had never studied computer programming before, so they had difficulty to learn basic functions in the first. To solve this problem, the teacher introduced the basic functions of MATLAB, gave instructions on how to program them as real examples, and guided the program in whole problem solving process.

The students showed a positive attitude toward the physical lesson using PBL as follow.

(1)It is interesting to solve with physics because it is real problem in daily life.

(2)Experienced that physical knowledge can be used in real life.

(3)Developed self-learning, cooperative learning and communication skills in the course of problem solving.

(4)Acquiring physical knowledge through problem solving, also learned how to solve problems. Hoping that this method will be helpful for solving real problems in the future.

(5)Abilities and skills of Presentation were greatly improved.

While students were faced with many difficulties during the course of applying PBL, there were times when they had difficulties and difficulties, they helped and led each other and made great progress in their ability to solve problems.

\section{CONCLUSION}

In Example of applying "problem-based learning" to "computational physics" class, we assume that the PBL class has the following significance:

\section{A. It is advantageous to induce students' interest in learning.}

The 'problem' in the PBL class is a physical problem in life that motivates students to engage in problem-solving through attracting their interests. The process of solving problems that have been encountered in daily life but which have not been physically interpreted by physics knowledge and solving methods enables students to experience processes similar to the process of solving scientific problems by scientists.

\section{B. Improving students' ability of solving problems.}

In order to solve unstructured problems in life, not only is it necessary to have abundant physical knowledge, but also the ability to apply the knowledge of various departments comprehensively. Therefore, in the course of PBL, students consolidate the knowledge they have already learned, and use it to solve problems. In this process, students will learn and control various problem-solving methods, and will be able to establish a basis for adapting the situation to other problems.

\section{It develops students' scientific attitude and cooperative spirit.}

Problems solved in the PBL class are in real situation, and there are many factors that affect the solution. Therefore, without a scientific attitude, problem solving is impossible. Students are deeply aware of this when they are faced with difficulties in solving problems with their own negligence. Scientific attitude toward problem solving is formed through these failures.

In addition, problem solving is done by team, And Harmonious co-operation among team members not only promotes problem solving, but also learns much from one another. The spirit of cooperation is a very necessary element in social life, and it underlies students' growth into a good society.

\section{Increase students' creativity.}

Unstructured problems have no fixed solution and process, And Students will be able to demonstrate their creativity in solving problems. Moreover, student will look for solutions that match their abilities and strengths, when solving problems that they are interested in. Of course, needed some appropriate guidance from teachers in the process of problem solving, but PBL course can help students discover and improve their creativity.

\section{REFERENCES}

[1] R.S.Donner and H.Bickley, "problem-based Learning in American Medical Education over View”, Bull Med Libr Assoc,vol, 81, pp. 294298, March 1993.

[2] J.S.Chung, "Use of project-based learning in physics education", SaeMulli(The Korean Physical Society), vol. 57, pp. 10-15, July 2008.

[3] Y.E.Kim, Y.J.Shin, H.J.Yoon and A.J.Woo, "The effect of problembased learning applied to the inorganic chemistry laboratory classes", Journal of the Korean Chemical Society, vol, 54, pp. 771-780, June 2010.

[4] S.Y.Ryu, "Case study: problem-based learning in business education”, Journal of Educational Technology, vol. 29, pp. 103-131, March 2013.

[5] S.H.Lee, "A case study of the Japanese communication by the method Of PBL”, The Jopurnal of the Institute of Humanities, vol, 28, pp. 176188, April 2014.

[6] J.-I.Choi, "A csae study for the application of PBL in higher-education: focused on the effectiveness of PBL presented in reflective journal", Journal of Educational Technology, vol. 23, pp. 35-65, June 2007.

[7] J.Chen, "Application of PBL Mode in College Physics Teaching”, Journal of Ningbo Institute of Education, vol, 18, pp. 12-14, august 2016.(In Chinese) 